\title{
Intervention Thresholds for Treatment in Patients with Glucocorticoid-Induced Osteoporosis: Systematic Review of Guidelines
}

\author{
Tae-Han Lee, Yeo-Jin Song, Hyoungyoung Kim, Yoon-Kyoung Sung, Soo-Kyung Cho \\ Department of Rheumatology, Hanyang University Hospital for Rheumatic Diseases, Seoul, Korea
}

\author{
Corresponding author \\ Soo-Kyung Cho \\ Department of Rheumatology, Hanyang \\ University Hospital for Rheumatic Diseases, \\ 222-1 Wangsimni-ro, Seongdong-gu, Seoul \\ 04763, Korea \\ Tel: +82-2-2290-9250 \\ Fax: +82-2-2298-8231 \\ E-mail: skchomd@hanyang.ac.kr
}

Received: September 14, 2020

Revised: October 19, 2020

Accepted: October 26, 2020
Copyright $@ 2020$ The Korean Society for Bone and Mineral Research

This is an Open Access article distributed under the terms of the Creative Commons Attribution Non-Commercial License (https://creativecommons.org/licenses/by-nc/4.0/) which permits unrestricted non-commercial use, distribution, and reproduction in any medium, provided the original work is properly cited.

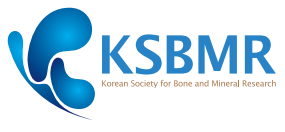

Background: In this study, we aimed to evaluate and compare the treatment indication for patients with glucocorticoid-induced osteoporosis (GIOP) in various clinical practice guidelines. Methods: We searched for potentially relevant studies conducted from January 2000 to March 2020 using online databases, including PubMed, Ovid-EMBASE, Guidelines International Network, National Institute for Health and Clinical Excellence, KoreaMed, KMbase, and KoMGI. We reviewed and analyzed the guidelines that included recommendations on GIOP and fulfilled the inclusion criteria. Results: A total of 94 articles were selected based on review of the title and abstract; 14 guidelines were assessed upon reviewing the full text. The bone mineral density score for therapeutic intervention of GIOP in postmenopausal women was presented in 7 guidelines, among which 3 guidelines set a T-score of -2.5 or lower and the other 4 guidelines proposed a less stringent cut-off point of -1.5 or lower. Among the 10 guidelines published since 2012 after the emergence of the fracture risk assessment tool (FRAX), 6 guidelines included FRAX in their criteria for defining intervention thresholds. However, they were further divided into fixed-probability $(n=3)$ and age-dependent $(n=3)$ thresholds based on the country. Conclusions: Recently developed guidelines use FRAX as the criterion for establishing the treatment of patients with GIOP. However, these intervention thresholds need to be adapted for each country.

Key Words: Glucocorticoids · Osteoporosis · Guideline · Systematic review · Intervention threshold

\section{INTRODUCTION}

Glucocorticoids (GCs) are used in a wide range of clinical settings and play a major role in the treatment of various inflammatory diseases.[1] In the USA, an estimated $1.2 \%$ of the general population uses GCs chronically.[2] For rheumatic diseases, GCs are one of the most frequently prescribed drugs, and a previous study using a large nationwide cohort in Korea reported that up to $83 \%$ of patients with rheumatoid arthritis (RA) were receiving or had received GC therapy.[3]

Long-term GC use is associated with loss of bone density and deterioration of bone microstructure leading to increased fracture risk, primarily in the trabecular bones such as vertebrae.[4,5] Although the fracture risk increases with the dose and duration of GC use, the risk increases most rapidly within 3 to 6 months of ini- 
tiation of oral GC therapy.[6,7] Therefore, early intervention strategies for GC-induced osteoporosis (GIOP) are critical for preventing fractures. $[4,8]$

Numerous guidelines for the management of GIOP patients have been published and updated by each country and academic society.[9] Some guidelines did not differentiate GC users from the general population. They use the fracture risk assessment tool (FRAX) for fracture risk assessment, and it reflects GC use as a risk factor.[10] On the other hand, some GIOP-specific guidelines have been developed separately from the guidelines for postmenopausal women, and these provide distinct threshold values.[11]

The Korean GIOP guidelines were recently developed by adapting established guidelines from other countries, but intervention thresholds had not been fully investigated. [12] Because it is important to grasp appropriate thresholds to prevent fractures during exposure to GCs, we systematically reviewed societal and national guidelines for GIOP and compared intervention thresholds in each guideline.

\section{METHODS}

\section{Data sources and guideline selection}

\section{1) Data source and search strategy}

We conducted a comprehensive search for relevant studies published from January 2000 to February 2020 using electronic databases. The databases included PubMed, Ovid-EMBASE, Guidelines International Network, National Institute for Health and Clinical Excellence, and 3 Korean databases (KoreaMed, KMbase, and KoMGI).

The search strategy was based on the Preferred Items for Systematic Reviews and Meta-Analyses (PRISMA) statement and followed the literature search process from the Korean GIOP guideline.[12,13] The terms used in MeSH and freetext searches were categorized into 3 concepts: "glucocorticoids," "osteoporosis," and "guideline."The terms corresponding to each concept were searched individually and then integrated together with the Boolean term "AND" (Supplementary Appendix 1). Additional manual searches for national guidelines posted on the International Osteoporosis Foundation website (https://www.iofbonehealth.org/national-regional-osteoporosis-guidelines) as well as for references cited in the selected relevant studies were carried out. The last search date was March 1, 2020.

\section{2) Inclusion and exclusion criteria}

Studies were included in this review if they met all of the following criteria: (1) identified themselves as guidelines; (2) contained recommendations for GC users; (3) provided intervention thresholds for GIOP; and (4) were in accordance with evidence-based methods. Studies were excluded if they (1) did not involve humans; (2) were limited to pediatric patients or a specific group of patients such as those with cancer, endocrine diseases, or human immunodeficiency virus infection; (3) were developed by a single author without appropriate representation or were based on simple consensus without systematic search; and (4) were not written in English or Korean. Potentially relevant papers were assessed for eligibility by screening the title and abstract, and then they were finally selected after full-text review on the basis of the predefined selection criteria. When there were several editions of guidelines from the same organization, the most recent one was selected. The literature searching and selection process was initially performed by 1 review author (THL) and subsequently checked by the other author (YJS). Disagreements were resolved by discussion between the 2 authors (THL and YJS).

\section{Quality assessment}

The quality of the development process in the guidelines was assessed using the domain for "rigor of development" in the Appraisal of Guidelines Research and Evaluation II (AGREE II) instrument.[14] This domain is based on the following 8 items: (1) systematic methods used to search for evidence; (2) criteria for selecting the evidence; (3) strengths and limitations of the evidence; (4) methods for formulating the recommendations; (5) health benefits, side effects, and risks of recommendations; (6) explicit links between the recommendations and the supporting evidence; (7) external expert reviewers; and (8) procedures for updating the guideline. Each item was rated by 2 independent appraisers on a 7-point scale, in which 1 point represents strongly disagree and 7 points represent strongly agree. A standardized score was calculated by summing up the individual items in each domain and scaling the total as a percentage of the maximum possible score for the domain. The authors considered the development process in each guideline to be rigorous if the average score was at least $50 \%$. 


\section{Recommendation extraction and analysis}

We extracted data from each included guideline pertaining to the characteristics of the guidelines (e.g., development organization, year of publication, applicable country or region, scope of osteoporosis, patient group), recommendations related to initial fracture risk assessment, recommendations related to intervention thresholds, and recommendations related to follow-up fracture risk assessment.

The recommendations for the assessment of clinical risk factors, such as falls, frailty, malnutrition, weight loss or low body weight, history of alcohol use or smoking, and other clinical comorbidities were omitted in this review, and we examined mainly instrumental assessments, i.e., bone mineral density (BMD) or FRAX. In addition, data on the drugs for osteoporosis treatment were not extracted.

Considering the study design of this review, where meta-analysis or statistical analysis was not appropriate, a narrative synthesis of data to summarize and describe systematic review results was conducted. The investigation of similarities and differences between guidelines, and comparison of recommendations related to the topic were undertaken. Then, further analysis of the supporting evidence reflected in determining intervention thresholds was followed.

\section{RESULTS}

\section{Guideline selection}

The flow diagram in Figure 1 shows the process of screening and selecting the guidelines. The initial search retrieved 887 citations, of which 796 papers were identified as potentially relevant after removing duplicates from the databases. Among them, 94 studies remained eligible after screening their titles and abstracts. The subsequent full-text review excluded 27 studies that did not deal with GIOP or include intervention thresholds, 8 studies that did not perform an evidence-based systematic search, 6 studies that were narrative reviews or were produced by a single author without appropriate representation, 1 study that was limited to a specific population, and 32 studies that were written in languages other than English or Korean. We excluded 7 guidelines which were previous versions published by the same organization, and the latest guidelines were selected. The manual search identified 1 additional guide-

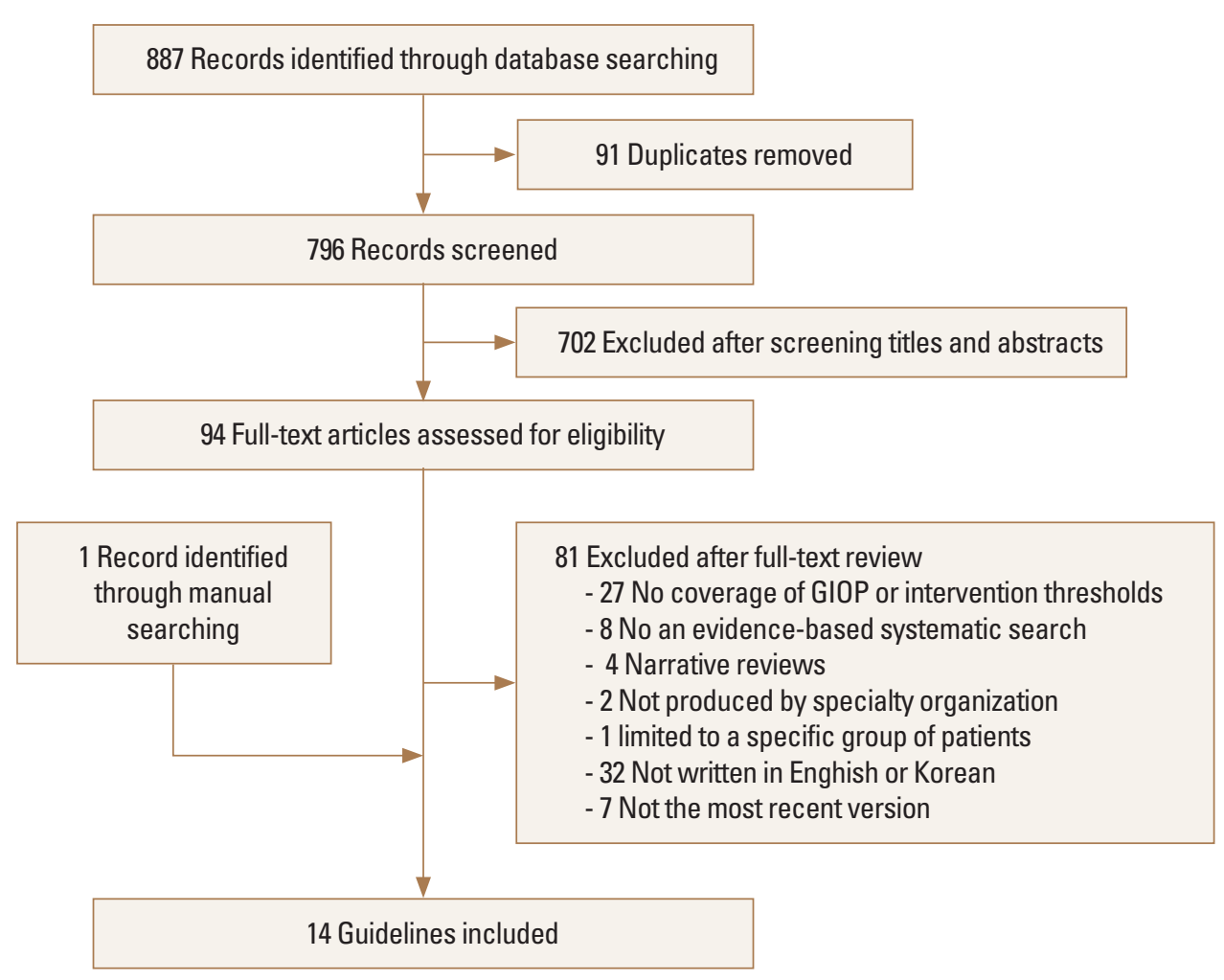

Fig. 1. Flow chart of the literature selection process. GIOP, glucocorticoid-induced osteoporosis. 
line. As a result, 14 guidelines were finally included in our analysis.[10-12,15-25]

\section{General characteristics of guidelines}

The characteristics of the 14 selected guidelines are summarized in Table 1. The guidelines were published between 2002 and 2019. Eight of the guidelines were developed specifically for GIOP $[11,12,15,16,19-22]$ whereas 6 cover overall osteoporosis including GIOP.[10,17,18,23-25] Of these guidelines, 5 were newly developed $[12,15,16,19,20]$ and the rest were updated guidelines.

The thresholds for initiating anti-osteoporosis intervention in patients receiving or starting long-term GC therapy are based on the following criteria: $G C$ dose and duration of use, age, prior fragility fracture, BMD score using dual energy X-ray absorptiometry (DXA), and FRAX score (Table 1).

\section{Appraisal of each guideline}

The scores for the AGREE II rigor of development of the included guidelines varied considerably, ranging from $12 \%$ to $75 \%$ with an average score of $28 \%$ (with the exception of the Dachverband Osteologie e.V. [DVO] guidelines, whose development process was only available in German) (Supplementary Appendix 2). A high degree of reliability was found between the 2 appraisers' scores, with an intraclass correlation coefficient of 0.96 ( $95 \%$ confidence interval 0.73 $0.99, P<0.001)$. According to the scores, only 5 guidelines (2018 the Korean Society for Bone and Mineral Research/ Korean College of Rheumatology [KSBMR/KCR], 2017 the American College of Rheumatology [ACR], 2017 the National Osteoporosis Guideline Group [NOGG], 2010 the Osteoporosis Canada, and 2002 the Royal College of Physicians) achieved a score of $50 \%$ or above, and the ACR guidelines scored the highest. These 5 guidelines were based on systematic reviews of published data, together with expert consensus, and followed nationally or internationally accepted quality assessment methods to develop their recommendations (Supplementary Appendix 3).

However, because the AGREE instrument primarily reflects the process involved in asking key questions with respect to "with what agent," it was difficult to clearly assess the evidence for determining the thresholds for "who to treat." Thus, we examined and described the intervention thresholds from all 14 guidelines in detail, rather than reviewing only the guidelines that we considered to be rig- orously developed.

\section{The assessment of fracture risk and intervention thresholds in each guideline}

1) Initial assessment of fracture risk for GC users

The recommendations extracted from the guidelines for initial fracture risk assessment in the management and prevention of GIOP are shown in Table 2. The contents of clinical fracture risk assessment, such as details of GC use, evaluation for falls, fractures, frailty, and other osteoporosis risk factors are not included. Most guidelines recommend an assessment for fracture prediction in individuals beginning or continuing GC treatment for more than 3 months.

Five guidelines, which were mostly published before 2012, propose BMD assessment as a single tool for identifying individuals at high risk for fractures.[15,17-19,22] On the other hand, recently revised or developed guidelines recommend that the initial fracture risk should be estimated using the FRAX score adjusted for GC dose and BMD values.[10-12,20,25] Some of these guidelines suggest that BMD testing could be performed conditionally depending on the results of the FRAX-based fracture probabilities. For example, the NOGG provides an algorithm to perform BMD measurements using DXA when an individual is at intermediate risk calculated by the FRAX model, and then reestimate the fracture probability using FRAX.[10] A similar approach is suggested by the Spanish Society of Rheumatology (SER), which suggests that bone densitometry is required if the 10-year probability of major osteoporotic fracture using FRAX is greater than 5\%.[25]

The recommendations in most guidelines discuss postmenopausal women and men aged over 50 or 60 . The guidelines from the ACR and the KSBMR/KCR present recommendations for younger patients separately. They suggest that BMD should be checked in adults under 40 who are at high fracture risk due to a history of previous osteoporotic fracture or a significant accompanying osteoporosis risk factor. $[11,12]$

\section{2) Intervention thresholds}

We extracted the recommendations for thresholds based on FRAX and BMD and the details of GC use from the guidelines (Table 2). Half the guidelines published before 2012 use only a single criterion for the threshold concerning the use of GCs, while recently published guidelines employ 


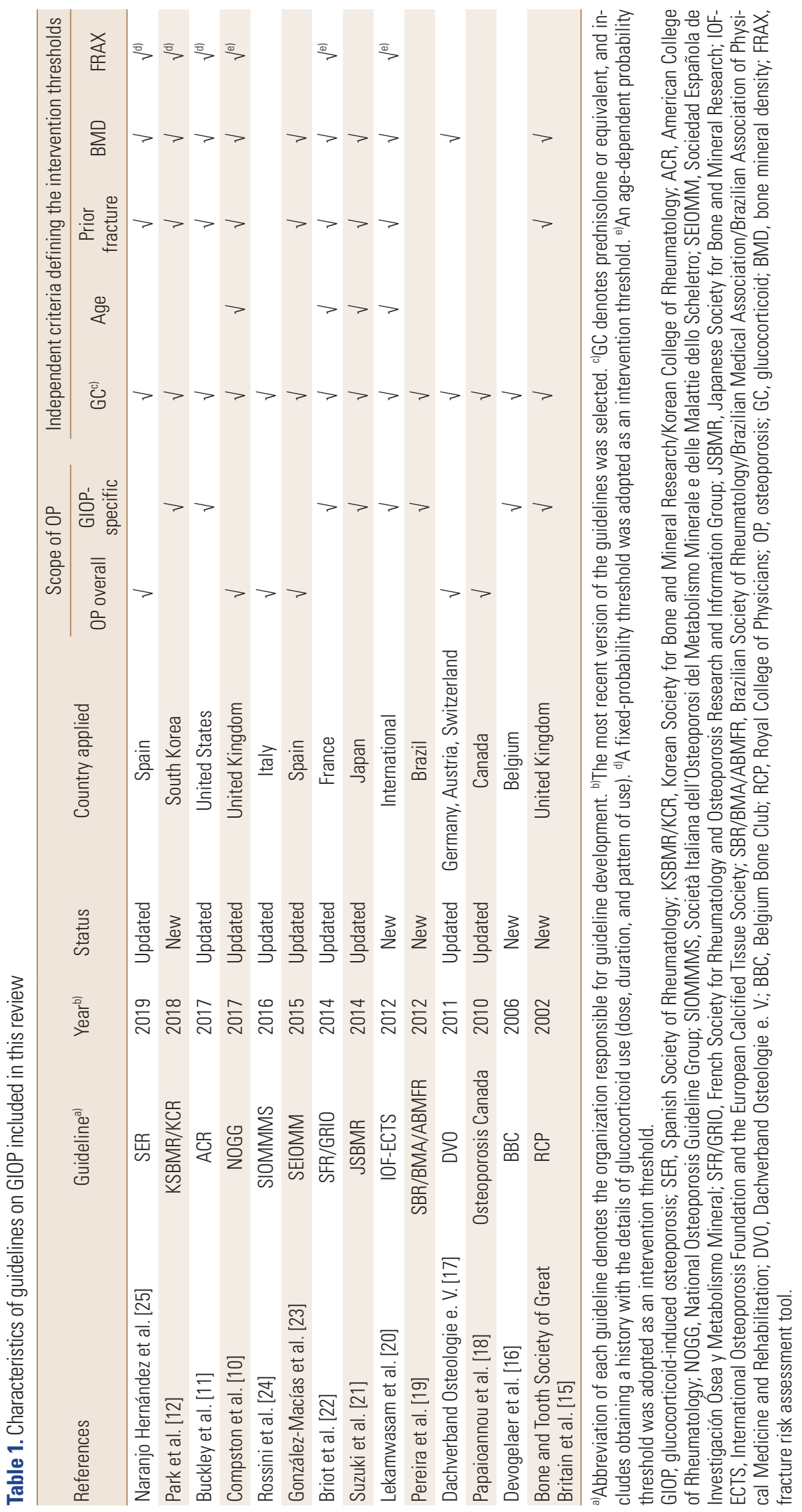




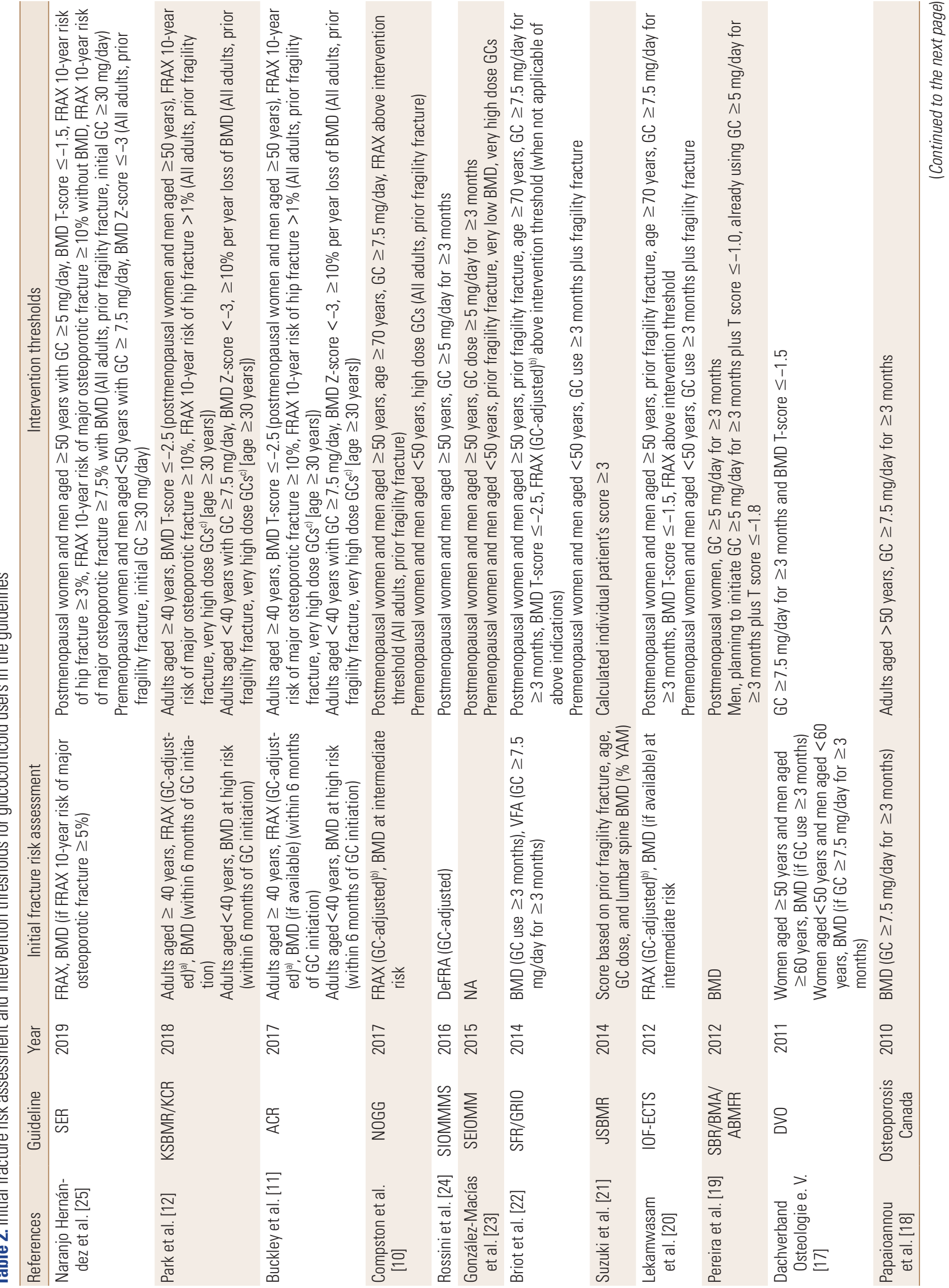




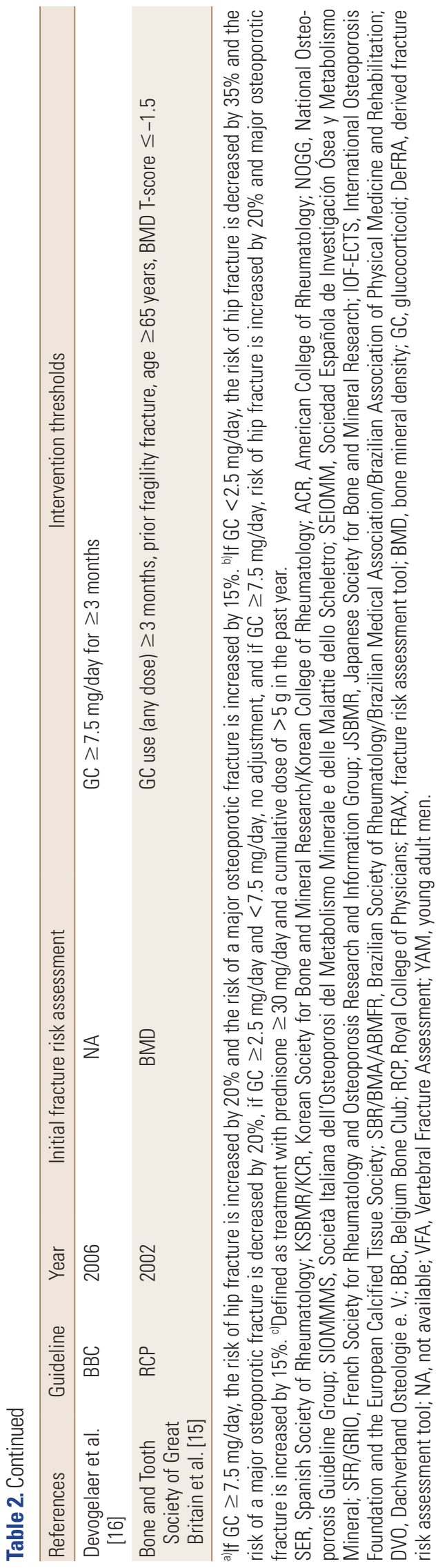

various criteria for defining thresholds. Six out of 10 guidelines published after 2012 (6 GIOP-specific and 4 overall osteoporosis) adopt FRAX as the main criteria for deciding who should be treated.[10-12,20,22,25]

A dose greater than 5 or $7.5 \mathrm{mg}$ of prednisone equivalents per day with a 3-month minimum duration was proposed as a threshold for preventive therapy in most guidelines.[10,15-20,22-24] In addition, it was recommended that GC users with a prior fragility fracture start anti-osteoporosis intervention regardless of other risk factors.[10-12, $15,20-23,25]$ Regardless of presence of previous fragility fracture, patients aged over 65 or 70 years would also be eligible for treatment.[10,15,20,22]

Of the 7 guidelines which include BMD score as a threshold for pharmacological therapy for postmenopausal women, 4 guidelines proposed a T-score threshold of -1.5 or less. $[15,17,20,25]$ However, the French Society for Rheumatology and Osteoporosis Research and Information Group (SFR/GRIO), ACR, and KSBMR/KCR guidelines set a T-score threshold of -2.5 or less, which is the same value usually accepted as postmenopausal osteoporosis, instead of a less stringent T-score threshold.[11,12,22]

For FRAX, the intervention thresholds in each guideline are divided into age-dependent thresholds and fixed-thresholds. Adjustments of FRAX for GC dose and BMD values (if available) are consistently recommended in the guidelines. The International Osteoporosis Foundation and the European Calcified Tissue Society (IOF-ECTS), SFR/GRIO, and NOGG guidelines adopted an age-dependent approach to intervention thresholds.[10,20,22] These guidelines state that pharmacological intervention is recommended for postmenopausal women and men over 50 years of age whose 10-year probability of fracture estimated by the FRAX tool exceeds the intervention threshold at a given age. However, a fixed-probability intervention threshold was used in guidelines from the ACR, KSBMR/KCR, and SER. $[11,12,25]$ The $A C R$ and KSBMR/KCR guidelines use fixed intervention thresholds set at a $10 \%$ probability for a major osteoporotic fracture and a $1 \%$ probability for a hip fracture.[11,12] In the SER guidelines, therapeutic intervention is recommended for individuals taking more than $5 \mathrm{mg}$ of prednisone per day if the 10-year probability of a major osteoporotic fracture is greater than $10 \%$ without BMD or $7.5 \%$ with BMD.[25] 
Table 3. Reassessment of fracture risk for prolonged glucocorticoids users in the guidelines

\begin{tabular}{|c|c|c|c|}
\hline References & Guideline & Year & Follow-up fracture risk assessment ${ }^{\text {a) }}$ \\
\hline Naranjo Hernández et al. [25] & SER & 2019 & NA \\
\hline Park et al. [12] & KSBMR/KCR & 2018 & $\begin{array}{l}\text { Adults aged } \geq 40 \text { years, never treated with } \mathrm{OP} \text { medication: FRAX with BMD every 1-3 } \\
\text { years, during OP medication: BMD every 2-3 years at high risk }{ }^{\mathrm{a}} \text {, completed OP medica- } \\
\text { tion: } \mathrm{BMD} \text { every 2-3 years } \\
\text { Adults aged }<40 \text { years, moderate-to-high risk }{ }^{\mathrm{b}} \text { : BMD every 2-3 years }\end{array}$ \\
\hline Buckley et al. [11] & ACR & 2017 & $\begin{array}{l}\text { Adults aged } \geq 40 \text { years, never treated with } \mathrm{OP} \text { medication: FRAX with BMD every 1-3 } \\
\text { years, during OP medication: BMD every 2-3 years at high risk }{ }^{\mathrm{a}} \text {, completed OP medica- } \\
\text { tion: BMD every 2-3 years } \\
\text { Adults aged }<40 \text { years, moderate-to-high risk }{ }^{\mathrm{b}} \text { : BMD every 2-3 years }\end{array}$ \\
\hline Compston et al. [10] & NOGG & 2017 & NA \\
\hline Rossini et al. [24] & SIOMMMS & 2016 & NA \\
\hline González-Macías et al. [23] & SEIOMM & 2015 & $\mathrm{BMD}$ at shorter intervals than postmenopausal OP \\
\hline Briot et al. [22] & SFR/GRIO & 2014 & $\begin{array}{l}\text { BMD annually during the first } 2 \text { years, then adjusted interval according to the BMD values, } \\
\text { GC dose, and underlying disease activity, spine X-ray or VFA if height loss } \geq 2 \mathrm{~cm} \text { or with } \\
\text { back pain }\end{array}$ \\
\hline Suzuki et al. [21] & JSBMR & 2014 & X-ray and BMD every 6-12 months \\
\hline Lekamwasam et al. [20] & IOF-ECTS & 2012 & BMD at appropriate intervals, X-ray or VFA if vertebral fracture suspected \\
\hline Pereira et al. [19] & $\begin{array}{l}\text { SBR/BMA/ } \\
\text { ABMFR }\end{array}$ & 2012 & $\begin{array}{l}\text { BMD, spine X-ray or VFA every } 6 \text { months during the first year of GC use, then every 1-2 } \\
\text { years }\end{array}$ \\
\hline $\begin{array}{l}\text { Dachverband Osteologie e. V. } \\
\text { [17] }\end{array}$ & DVO & 2011 & $\begin{array}{l}\mathrm{BMD} \text { at intervals of } 6-12 \text { months in patients without } \mathrm{OP} \text { medication, if } \mathrm{GC} \geq 7.5 \mathrm{mg} / \text { day } \\
\text { continued, } \mathrm{BMD} \text { at shorter intervals (up to } 6 \text { months) in patients undergoing drug treat- } \\
\text { ment, if } \mathrm{GC} \geq 7.5 \mathrm{mg} / \text { day continued }\end{array}$ \\
\hline Papaioannou et al. [18] & $\begin{array}{l}\text { Osteoporosis } \\
\text { Canada }\end{array}$ & 2010 & BMD every $1-3$ years \\
\hline Devogelaer et al. [16] & $\mathrm{BBC}$ & 2006 & NA \\
\hline $\begin{array}{c}\text { Bone and Tooth Society of } \\
\text { Great Britain et al. [15] }\end{array}$ & $\mathrm{RCP}$ & 2002 & Spinal BMD \\
\hline
\end{tabular}

a)Individuals with very high-dose GCs, or fragility fracture occurring after $\geq 18$ months of osteoporosis medication, poor medication adherence or absorption, or other osteoporosis risk factors. ${ }^{b}$ Individuals with prior fragility fracture, or BMD Z-score $<-3, \geq 10 \%$ per year loss of BMD, very high-dose GCs, poor medication adherence or absorption, or other osteoporosis risk factors.

SER, Spanish Society of Rheumatology; KSBMR/KCR, Korean Society for Bone and Mineral Research/Korean College of Rheumatology; ACR, American College of Rheumatology; NOGG, National Osteoporosis Guideline Group; SIOMMMS, Società Italiana dell'Osteoporosi del Metabolismo Minerale e delle Malattie dello Scheletro; SEIOMM, Sociedad Española de Investigación Ósea y Metabolismo Mineral; SFR/GRIO, French Society for Rheumatology and Osteoporosis Research and Information Group; JSBMR, Japanese Society for Bone and Mineral Research; IOF-ECTS, International Osteoporosis Foundation and the European Calcified Tissue Society; SBR/BMA/ABMFR, Brazilian Society of Rheumatology/Brazilian Medical Association/Brazilian Association of Physical Medicine and Rehabilitation; DVO, Dachverband Osteologie e. V.; BBC, Belgium Bone Club; RCP, Royal College of Physicians; NA, not available; OP, osteoporosis; FRAX, fracture risk assessment tool; BMD, bone mineral density; GC, glucocorticoid; VFA, Vertebral Fracture Assessment.

\section{3) Follow-up assessment}

We identified the recommendations from 10 guidelines regarding the reassessment of fracture risk for individuals who continue GC treatment (Table 3). Most guidelines suggest regular measurements of BMD. A morphological assessment, such as spine X-ray or Vertebral Fracture Assessment (VFA) along with DXA, should also be considered if a vertebral fracture is suspected.[19,20,22] The interval for BMD testing varies from 6 months to 3 years depending on the guidelines. The approaches to re-evaluating fracture risk according to age or status of intervention are available in the recommendations from the ACR and KS-
BMR/KCR guidelines.[11,12]

\section{DISCUSSION}

We reviewed recommendations with regard to intervention thresholds in both GIOP-specific guidelines and overall osteoporosis guidelines. Although recommendations are based on the rationale that the association of fracture risk with GCs is exposure-dependent, thresholds vary among the guidelines. The criteria for defining intervention thresholds were refined in accordance with the development of fracture risk assessment tools. Before the introduction of 
FRAX, intervention thresholds were based on the degree of GC exposure or BMD score. However, over time, the criteria for identifying patients who should receive preventive treatment has shifted towards country-specific FRAX values.

Previous epidemiological studies have demonstrated that the increased risk of vertebral and nonvertebral fracture is related to GC dose and exposure.[4,5,8] Even doses as low as 2.5 or $7.5 \mathrm{mg}$ of prednisone-equivalents per day can be associated with a 2.5 -fold increase in vertebral fractures and 1.7-fold increase in hip fractures.[4] The risk increases rapidly within 3 to 6 months after the start of GCs and is greater in patients exposed to higher doses continuously for a longer period. $[7,8,26]$ In accordance with these results, thresholds of 5 or $7.5 \mathrm{mg}$ per day with a duration for 3 months or greater are consistently accepted in the most guidelines, and an initial clinical fracture risk assessment as soon as possible within 6 months of GC initiation is strongly recommended.[11,12]

The conventional BMD T-score of -2.5 is usually applied to the guidelines for postmenopausal osteoporosis treatment; however, some guidelines apply less stringent T-score values because the fracture risk is much higher in GIOP compared to that expected based on DXA values. $[27,28]$ At similar BMD levels, the incidence of vertebral fractures in postmenopausal women was considerably higher in GC users than nonusers.[27] Moreover, in a meta-analysis of international cohorts, a direct relationship between BMD score and fracture risk was not verified in GIOP.[28] GCs have adverse effects on trabecular bone microarchitecture independent of BMD and the changes in the bone quality that contribute to increased risk of fracture often do not translate into a decrease in BMD scores.[29-31] Although these findings provide the rationale for a T-score threshold different from that of postmenopausal osteoporosis, there is no established T-score threshold for bone-protective therapy in patients taking GCs. From the earlier guidelines, T-score thresholds of -1.0 or -1.5 were included as an independent criterion for intervention with pharmacological treatment.[15,32] Thereafter, the same values have been adopted by numerous guidelines.[17,19,20,25]

However, the higher BMD cut-off point is not an evidencebased threshold, but rather an accepted value considering the discrepancy between BMD data and fracture data in GC users. It is unclear whether (and to what degree) the less stringent BMD threshold predicts fracture risk in individuals using GCs, and whether it is cost-effective in terms of drug therapy. Therefore, a more comprehensive approach beyond the BMD which considers various clinical risk factors for fracture is particularly important in GIOP.[33]

The recognition that consideration of independent risk factors and BMD together is more accurate in predicting fracture probability compared to BMD alone has led to the development of fracture risk tools that incorporate various clinical risk factors, including oral GCs.[34,35] Of these tools, FRAX is the most externally validated and widely used.[36] Since its release in 2008,[37] the use of FRAX combined with intervention thresholds has been recommended by many national and societal postmenopausal osteoporosis treatment guidelines.[10,18,24,25,38] The ACR has also incorporated FRAX as an assessment tool for fracture risk in GIOP in its 2010 revised guidelines.[39] Furthermore, in 2012, the joint Guideline Working Group of the IOF-ECTS suggested a fracture probability-based approach using FRAX in its framework for the development of guidelines for GIOP management.[20]

The dose relationship between GC use over 3 months and fracture risk can be employed in the FRAX model, which allows the estimates to be adjusted depending on GC dose. $[40,41]$ FRAX assumes an average dose of prednisone (2.5$7.5 \mathrm{mg} /$ day or its equivalent) and adjustments according to doses have been proposed in several guidelines. In the 2017 NOGG guidelines, the average adjustment for postmenopausal women and men over 50 years of age is a factor of 0.8 for low-dose exposure and 1.15 for high-dose exposure for major osteoporotic fractures; these adjustment factors are 0.65 and 1.20 , respectively, for hip fractures.[10] However, since these adjustments may provide a limited estimate of the risk associated with very high-dose GC exposure, some guidelines additionally recommend pharmacological intervention in adults receiving very high-dose GCs, independent of BMD and FRAX values.[11,12,25]

In spite of these adjustments to overcome the limitations of the conventional FRAX algorithm, FRAX makes no distinction between past and current GC use and lacks the ability to estimate fracture risk in premenopausal women and men under 40. In addition, its predictive value for identifying individuals at high risk of fracture has been primarily validated for hip fractures.[42,43] Considering these limitations, FRAX was not incorporated into the revised Japa- 
nese guidelines.[21] In addition, like BMD values, FRAX also has a weakness with respect to its reproducibility in $\mathrm{GIOP}$, because the performance of the FRAX algorithm was validated for the general population. Although RA, which requires $\mathrm{GC}$ therapy and is itself a risk factor for fracture independent of GIOP,[44] is included as one of the dichotomous factors in the estimation of fracture risk, FRAX does not encompass disease activity and duration, which are significantly associated with increased fracture risk. $[45,46]$ Thus, its application of the same thresholds derived from the general population to patients with GIOP, or to patients with a specific disease that is itself a cause of osteoporosis, may result in a risk of error.[47]

Recently updated recommendations have suggested less stringent FRAX cut-off points than those for postmenopausal osteoporosis for determining when anti-osteoporosis intervention is in order.[11,12,25] The 2017 ACR guidelines recommend pharmacological intervention in patients with a 10-year major osteoporotic fracture risk of greater than $10 \%$ or a 10 -year hip fracture risk of greater than $1 \%$. The thresholds of $10 \%$ and $1 \%$ are lower than the generally accepted thresholds of $20 \%$ and $3 \%$ for postmenopausal osteoporosis.[38] The guideline developers made recommendations based on absolute fracture risk reduction with treatment in each stratum, classified according to the incidence of vertebral fractures over 5 years. However, fracture data is lacking in GIOP-specific clinical trials and population studies; therefore, most fracture data for these recommendations were extrapolated from general osteoporosis clinical trials.[11] The 2017 NOGG guidelines suggest an age-dependent intervention threshold using FRAX, not a fixed-threshold. This approach is based on the rationale that if a woman with a prior fragility fracture is eligible for treatment, then, at any given age, a woman with the same fracture probability but in the absence of a previous fracture should also be eligible.[48] Given the cost-effectiveness of this case-finding strategy in the UK, where provision for BMD testing is suboptimal, an age-dependent fracture probability determines the thresholds at which to intervene both for treatment and for BMD testing. $[48,49]$ The same strategies are recommended for individuals taking GCs, with an additional independent threshold that patients exposed to greater than $7.5 \mathrm{mg}$ of prednisoneequivalents per day are eligible for therapeutic intervention.[10] However, fracture risk might be underestimated in patients who have been treated for a long time with a lower dose of GCs when the NOGG guidelines are applied. In addition, recommendations for intervention thresholds in younger GC users are rather limited.

The discrepancies between the 2 main guidelines on GIOP arise from diversity in local conditions, such as health care policies, cost of treatment, and accessibility to BMD, as well as different fracture probabilities across the countries. However, the majority of guidelines, especially using a fixed-FRAX probability, have adopted an identical threshold value as the USA, without their own health economic analysis.[48] The paucity of data on GIOP-induced fractures makes it difficult to develop evidence-based guidelines in other countries as well, with a great variation in rigor scores among the guidelines.

In Korea, the 2018 guidelines for GIOP prevention and treatment contain the accepted thresholds of FRAX and BMD which were suggested by the ACR. Given the lack of domestic data, the working group decided to adapt previously published guidelines and presented the same intervention thresholds from the 2017 ACR guidelines.[12] After its publication, the Health Insurance Review \& Assessment Service in Korea announced that pharmacological intervention for the prevention of fracture is available for prolonged GC users whose BMD T-score is -1.5 or less.[50] To set the best target for intervention in patients taking GCs while considering cost-effectiveness, it is necessary to consider the benefits and limitations of FRAX and BMD, accessibility to BMD testing, and other clinical risk factors in the context of GIOP-induced fracture in order to set the appropriate thresholds.

Despite a sensitive search strategy for eligible guidelines, explicit selection criteria for eligibility, and appraisal of the guidelines using the AGREE II instrument, several limitations could have biased our findings. First, only guidelines written in English were included, and guidelines written in other languages may have been overlooked. Second, the National Guideline Clearinghouse, which is a public resource of evidence-based clinical practice guidelines and widely used for guideline searching, was not included in the search database because it was not available at the time of the literature search. Thus, we might have missed some eligible guidelines. Third, the quality of the evidence underpinning the recommendations was not investigated because the AGREE instrument evaluates the methodolog- 
ical rigor and transparency with which a guideline is developed and not the quality of its contents. Moreover, statements of the strengths and limitations of data in the guidelines were mainly concerned with anti-osteoporosis drugs. For this reason, a comprehensive investigation of previous studies supporting the recommendations was performed to identify the evidence underpinning the effectiveness of thresholds for therapeutic intervention in the current GIOP guidelines.

In conclusion, the results of our review showed that GIOP guidelines have proposed thresholds distinct from those of postmenopausal osteoporosis, given the natural history of bone loss caused by GCs. Since the introduction of FRAX, a FRAX-based approach has been incorporated into the criteria for defining intervention thresholds. However, highquality data pertaining to these thresholds that can warrant intervention in GC-treated patients are still limited. Further studies assessing fracture as a primary outcome with established tools, such as FRAX and DXA, in chronic GC users could aid in setting tailored intervention thresholds in GIOP guidelines.

\section{DECLARATIONS}

\section{Acknowledgments}

This research was supported by a grant of Patient-Centered Clinical Research Coordinating Center funded by the Ministry of Health \& Welfare, Republic of Korea (grant number: HI19C0481, HC19C0047).

\section{Ethics approval and consent to participate}

The review was exempted by the institutional review board of our university hospital because of the retrospective nature of our study, which used existing data or documents for research (IRB No. HYUH 2020-07-05).

\section{Conflict of interest}

No potential conflict of interest relevant to this article was reported.

\section{ORCID}

Tae-Han Lee https://orcid.org/0000-0001-7455-9534

Yeo-Jin Song https://orcid.org/0000-0001-9420-2129 Hyoungyoung Kim https://orcid.org/0000-0003-1415-461X Yoon-Kyoung Sung https://orcid.org/0000-0001-6691-8939
Soo-Kyung Cho https://orcid.org/0000-0003-4493-8837

\section{REFERENCES}

1. Fardet L, Petersen I, Nazareth I. Prevalence of long-term oral glucocorticoid prescriptions in the UK over the past 20 years. Rheumatology (Oxford) 2011;50:1982-90. http:// dx.doi.org/10.1093/rheumatology/ker017.

2. Overman RA, Yeh JY, Deal CL. Prevalence of oral glucocorticoid usage in the United States: a general population perspective. Arthritis Care Res (Hoboken) 2013;65:294-8. http://dx.doi.org/10.1002/acr.21796.

3. Lee JH, Sung YK, Choi CB, et al. The frequency of and risk factors for osteoporosis in Korean patients with rheumatoid arthritis. BMC Musculoskelet Disord 2016;17:98. http: //dx.doi.org/10.1186/s12891-016-0952-8.

4. Van Staa TP, Leufkens HG, Abenhaim L, et al. Use of oral corticosteroids and risk of fractures. J Bone Miner Res 2000; 15:993-1000. http://dx.doi.org/10.1359/jbmr.2000.15.6.993.

5. van Staa TP, Leufkens HG, Abenhaim L, et al. Oral corticosteroids and fracture risk: relationship to daily and cumulative doses. Rheumatology (Oxford) 2000;39:1383-9. http ://dx.doi.org/10.1093/rheumatology/39.12.1383.

6. Dalle Carbonare L, Arlot ME, Chavassieux PM, et al. Comparison of trabecular bone microarchitecture and remodeling in glucocorticoid-induced and postmenopausal osteoporosis. J Bone Miner Res 2001;16:97-103. http://dx.doi. org/10.1359/jbmr.2001.16.1.97.

7. van Staa TP, Leufkens HG, Cooper C. The epidemiology of corticosteroid-induced osteoporosis: a meta-analysis. Osteoporos Int 2002;13:777-87. http://dx.doi.org/10.1007/ s001980200108.

8. Steinbuch M, Youket TE, Cohen S. Oral glucocorticoid use is associated with an increased risk of fracture. Osteoporos Int 2004;15:323-8. http://dx.doi.org/10.1007/s00198-0031548-3.

9. Compston J. Glucocorticoid-induced osteoporosis: an update. Endocrine 2018;61:7-16. http://dx.doi.org/10.1007/ s12020-018-1588-2.

10. Compston J, Cooper A, Cooper C, et al. UK clinical guideline for the prevention and treatment of osteoporosis. Arch Osteoporos 2017;12:43. http://dx.doi.org/10.1007/s11657017-0324-5.

11. Buckley L, Guyatt G, Fink HA, et al. 2017 American college of rheumatology guideline for the prevention and treat- 
ment of glucocorticoid-induced osteoporosis. Arthritis Rheumatol 2017;69:1521-37. http://dx.doi.org/10.1002/ art.40137.

12. Park SY, Gong HS, Kim KM, et al. Korean guideline for the prevention and treatment of glucocorticoid-induced osteoporosis. J Bone Metab 2018;25:195-211. http://dx.doi. org/10.11005/jbm.2018.25.4.195.

13. Liberati A, Altman DG, Tetzlaff J, et al. The PRISMA statement for reporting systematic reviews and meta-analyses of studies that evaluate health care interventions: explanation and elaboration. J Clin Epidemiol 2009;62:e1-34. http://dx.doi.org/10.1016/j.jclinepi.2009.06.006.

14. Brouwers MC, Kho ME, Browman GP, et al. AGREE II: advancing guideline development, reporting and evaluation in health care. CMAJ 2010;182:E839-42. http://dx.doi.org/ 10.1503/cmaj.090449.

15. Bone and Tooth Society of Great Britain, National Osteoporosis Society, Royal College of Physicians. Glucocorticoid-induced osteoporosis: guidelines for prevention and treatment. London, UK: Royal College of Physicians; 2002.

16. Devogelaer JP, Goemaere S, Boonen S, et al. Evidence-based guidelines for the prevention and treatment of glucocorticoid-induced osteoporosis: a consensus document of the Belgian Bone Club. Osteoporos Int 2006;17:8-19. http:// dx.doi.org/10.1007/s00198-005-2032-z.

17. Dachverband Osteologie e. V. DVO guideline 2009 for prevention, diagnosis and therapy of osteoporosis in adults: Full-text version. Osteologie 2011;20:55-74. http://dx.doi. org/10.1055/s-0037-1619980.

18. Papaioannou A, Morin S, Cheung AM, et al. 2010 clinical practice guidelines for the diagnosis and management of osteoporosis in Canada: summary. CMAJ 2010;182:186473. http://dx.doi.org/10.1503/cmaj.100771.

19. Pereira RM, Carvalho JF, Paula AP, et al. Guidelines for the prevention and treatment of glucocorticoid-induced osteoporosis. Rev Bras Reumatol 2012;52:580-93.

20. Lekamwasam S, Adachi JD, Agnusdei D, et al. A framework for the development of guidelines for the management of glucocorticoid-induced osteoporosis. Osteoporos Int 2012; 23:2257-76. http://dx.doi.org/10.1007/s00198-012-1958-1.

21. Suzuki Y, Nawata $H$, Soen $S$, et al. Guidelines on the management and treatment of glucocorticoid-induced osteoporosis of the Japanese Society for Bone and Mineral Research: 2014 update. J Bone Miner Metab 2014;32:337-50. http://dx.doi.org/10.1007/s00774-014-0586-6.
22. Briot K, Cortet B, Roux C, et al. 2014 update of recommendations on the prevention and treatment of glucocorticoid-induced osteoporosis. Joint Bone Spine 2014;81:493501. http://dx.doi.org/10.1016/j.jbspin.2014.10.001.

23. González-Macías J, Del Pino-Montes J, Olmos JM, et al. Clinical practice guidelines for posmenopausal, glucocorticoid-induced and male osteoporosis. Spanish Society for Research on Bone and Mineral Metabolism (3rd updated version 2014). Rev Clin Esp 2015;215:515-26. http://dx.doi. org/10.1016/j.rce.2015.08.003.

24. Rossini M, Adami S, Bertoldo F, et al. Guidelines for the diagnosis, prevention and management of osteoporosis. Reumatismo 2016;68:1-39. http://dx.doi.org/10.4081/reumatismo.2016.870.

25. Naranjo Hernández A, Díaz Del Campo Fontecha P, Aguado Acín MP, et al. Recommendations by the Spanish society of rheumatology on osteoporosis. Reumatol Clin 2019; 15:188-210. http://dx.doi.org/10.1016/j.reuma.2018.09.004.

26. De Vries F, Bracke M, Leufkens HG, et al. Fracture risk with intermittent high-dose oral glucocorticoid therapy. Arthritis Rheum 2007;56:208-14. http://dx.doi.org/10.1002/ art.22294.

27. Van Staa TP, Laan RF, Barton IP, et al. Bone density threshold and other predictors of vertebral fracture in patients receiving oral glucocorticoid therapy. Arthritis Rheum 2003;48:3224-9. http://dx.doi.org/10.1002/art.11283.

28. Kanis JA, Johansson $H$, Oden $A$, et al. A meta-analysis of prior corticosteroid use and fracture risk. J Bone Miner Res 2004;19:893-9. http://dx.doi.org/10.1359/jbmr.040134.

29. Leib ES, Winzenrieth R. Bone status in glucocorticoid-treated men and women. Osteoporos Int 2016;27:39-48. http: //dx.doi.org/10.1007/s00198-015-3211-1.

30. Saag KG, Agnusdei D, Hans D, et al. Trabecular bone score in patients with chronic glucocorticoid therapy-induced osteoporosis treated with alendronate or teriparatide. Arthritis Rheumatol 2016;68:2122-8. http://dx.doi.org/10.1002/ art.39726.

31. Canalis E, Mazziotti G, Giustina A, et al. Glucocorticoid-induced osteoporosis: pathophysiology and therapy. Osteoporos Int 2007;18:1319-28. http://dx.doi.org/10.1007/ s00198-007-0394-0.

32. American College of Rheumatology Ad Hoc Committee on Glucocorticoid-Induced Osteoporosis. Recommendations for the prevention and treatment of glucocorticoidinduced osteoporosis: 2001 update. Arthritis Rheum 2001; 
44:1496-503. http://dx.doi.org/10.1002/1529-0131(200107) 44:7<1496::Aid-art271>3.0.Co;2-5.

33. Briot K, Roux C. Glucocorticoid-induced osteoporosis. RMD Open 2015;1:e000014. http://dx.doi.org/10.1136/rmdopen-2014-000014.

34. Kanis JA. Diagnosis of osteoporosis and assessment of fracture risk. Lancet 2002;359:1929-36. http://dx.doi.org/ 10.1016/s0140-6736(02)08761-5.

35. Kanis JA, Harvey NC, Johansson $H$, et al. Overview of fracture prediction tools. J Clin Densitom 2017;20:444-50. http: //dx.doi.org/10.1016/j.jocd.2017.06.013.

36. Marques A, Ferreira RJ, Santos E, et al. The accuracy of osteoporotic fracture risk prediction tools: a systematic review and meta-analysis. Ann Rheum Dis 2015;74:1958-67. http://dx.doi.org/10.1136/annrheumdis-2015-207907.

37. Kanis JA, Johnell O, Oden A, et al. FRAX and the assessment of fracture probability in men and women from the UK. Osteoporos Int 2008;19:385-97. http://dx.doi.org/10.1007/ s00198-007-0543-5.

38. Cosman F, de Beur SJ, LeBoff MS, et al. Clinician's guide to prevention and treatment of osteoporosis. Osteoporos Int 2014;25:2359-81. http://dx.doi.org/10.1007/s00198-0142794-2.

39. Grossman JM, Gordon R, Ranganath VK, et al. American College of Rheumatology 2010 recommendations for the prevention and treatment of glucocorticoid-induced osteoporosis. Arthritis Care Res (Hoboken) 2010;62:1515-26. http://dx.doi.org/10.1002/acr.20295.

40. Leib ES, Saag KG, Adachi JD, et al. Official Positions for FRAX $\left({ }^{\circledR}\right)$ clinical regarding glucocorticoids: the impact of the use of glucocorticoids on the estimate by $\operatorname{FRAX}\left({ }^{\circledR}\right)$ of the 10 year risk of fracture from Joint Official Positions Development Conference of the International Society for Clinical Densitometry and International Osteoporosis Foundation on FRAX $\left({ }^{\circledR}\right)$. J Clin Densitom 2011;14:212-9. http:// dx.doi.org/10.1016/j.jocd.2011.05.014.

41. Kanis JA, Johansson $H$, Oden $A$, et al. Guidance for the adjustment of FRAX according to the dose of glucocorticoids. Osteoporos Int 2011;22:809-16. http://dx.doi.org/10.1007/ s00198-010-1524-7.

42. Dagan N, Cohen-Stavi C, Leventer-Roberts M, et al. External validation and comparison of three prediction tools for risk of osteoporotic fractures using data from population based electronic health records: retrospective cohort study. BMJ 2017;356:i6755. http://dx.doi.org/10.1136/ bmj.i6755.

43. Beaudoin C, Moore L, Gagné M, et al. Performance of predictive tools to identify individuals at risk of non-traumatic fracture: a systematic review, meta-analysis, and metaregression. Osteoporos Int 2019;30:721-40. http://dx.doi. org/10.1007/s00198-019-04919-6.

44. Wilson JC, Sarsour K, Gale S, et al. Incidence and risk of glucocorticoid-associated adverse effects in patients with rheumatoid arthritis. Arthritis Care Res (Hoboken) 2019; 71:498-511. http://dx.doi.org/10.1002/acr.23611.

45. Meng J, Li Y, Yuan X, et al. Evaluating osteoporotic fracture risk with the Fracture Risk Assessment Tool in Chinese patients with rheumatoid arthritis. Medicine (Baltimore) 2017; 96:e6677. http://dx.doi.org/10.1097/md.0000000000006677.

46. Phuan-Udom R, Lektrakul N, Katchamart W. The association between 10-year fracture risk by FRAX and osteoporotic fractures with disease activity in patients with rheumatoid arthritis. Clin Rheumatol 2018;37:2603-10. http:// dx.doi.org/10.1007/s10067-018-4218-8.

47. Lee JH, Cho SK, Han M, et al. Are glucocorticoid-induced osteoporosis recommendations sufficient to determine antiosteoporotic treatment for patients with rheumatoid arthritis? Korean J Intern Med 2014;29:509-15. http://dx. doi.org/10.3904/kjim.2014.29.4.509.

48. Kanis JA, Harvey NC, Cooper C, et al. A systematic review of intervention thresholds based on FRAX : A report prepared for the National Osteoporosis Guideline Group and the International Osteoporosis Foundation. Arch Osteoporos 2016;11:25. http://dx.doi.org/10.1007/s11657-0160278-z.

49. Kanis JA, McCloskey EV, Johansson $\mathrm{H}$, et al. Case finding for the management of osteoporosis with FRAX--assessment and intervention thresholds for the UK. Osteoporos Int 2008;19:1395-408. http://dx.doi.org/10.1007/s00198008-0712-1.

50. Suh $\mathrm{CH}$. Korean guideline of glucocorticoid-induced osteoporosis; Time to prevent fracture! J Rheum Dis 2019; 26:87-9. http://dx.doi.org/10.4078/jrd.2019.26.2.87. 
Tae-Han Lee, et al.

Supplementary Appendix 1. Search strategies for PubMed and Ovid-EMBASE

\begin{tabular}{|c|c|c|}
\hline No. & Search query & Results \\
\hline \multicolumn{3}{|c|}{ PubMed } \\
\hline \#1 & steroid[MeSH terms] & 846,711 \\
\hline \#2 & steroid*[TIAB] OR glucocorticoid*[TIAB] & 288,429 \\
\hline \#3 & $\# 10 R \# 2$ & $1,001,632$ \\
\hline \#4 & osteoporosis[MeSH terms] & 54,846 \\
\hline \#5 & osteoporos*[TIAB] OR osteopenia[TIAB] & 72,023 \\
\hline \#6 & "bone loss" OR "bone losses" & 35,264 \\
\hline$\# 7$ & $\# 4$ OR \#5 OR \#6 & 113,146 \\
\hline \#8 & \#3 AND \#7 & 15,903 \\
\hline \#9 & practice guideline[PT] OR guideline[PT] OR guideline*[TI] OR recommendation*[TI] OR standard*[TI] & 215,924 \\
\hline$\# 10$ & \#8 AND \#9 & 265 \\
\hline$\# 11$ & animals[MeSH terms] NOT humans[MeSH terms] & $4,670,734$ \\
\hline \#12 & $\# 10$ NOT \#11 & 256 \\
\hline$\# 13$ & Limit \#12 to yr= "2000-current" & 233 \\
\hline \multicolumn{3}{|c|}{ Ovid-EMBASE } \\
\hline$\# 1$ & steroids.mp. or exp steroid/ & $1,464,935$ \\
\hline$\# 2$ & glucocorticoids.mp. or exp glucocorticoid/ & 702,802 \\
\hline \#3 & (steroid* or glucocorticoid*).tw. & 383,900 \\
\hline$\# 4$ & $\# 1$ OR \#2 OR \#3 & $1,546,020$ \\
\hline$\# 5$ & osteoporosis.mp. or exp osteoporosis/ & 150,197 \\
\hline$\# 6$ & osteoporos*.tw. & 99,514 \\
\hline$\# 7$ & osteopenia.mp. or exp osteopenia/ & 23,259 \\
\hline \#8 & osteopenia.tw. & 15,161 \\
\hline$\# 9$ & bone loss.mp. or exp bone loss/ & 87,819 \\
\hline$\# 10$ & bone loss*.tw. & 36,627 \\
\hline$\# 11$ & $\# 5$ OR \# 6 OR \#7 OR \#8 OR \#9 OR \#10 & 220,345 \\
\hline$\# 12$ & $\# 4$ AND \#11 & 46,021 \\
\hline$\# 13$ & (guideline* or recommendation*).ti. & 143,716 \\
\hline$\# 14$ & $\# 12$ AND \#13 & 718 \\
\hline$\# 15$ & limit \#14 to human & 677 \\
\hline \#16 & limit \#15 to yr="2000 -Current" & 618 \\
\hline
\end{tabular}




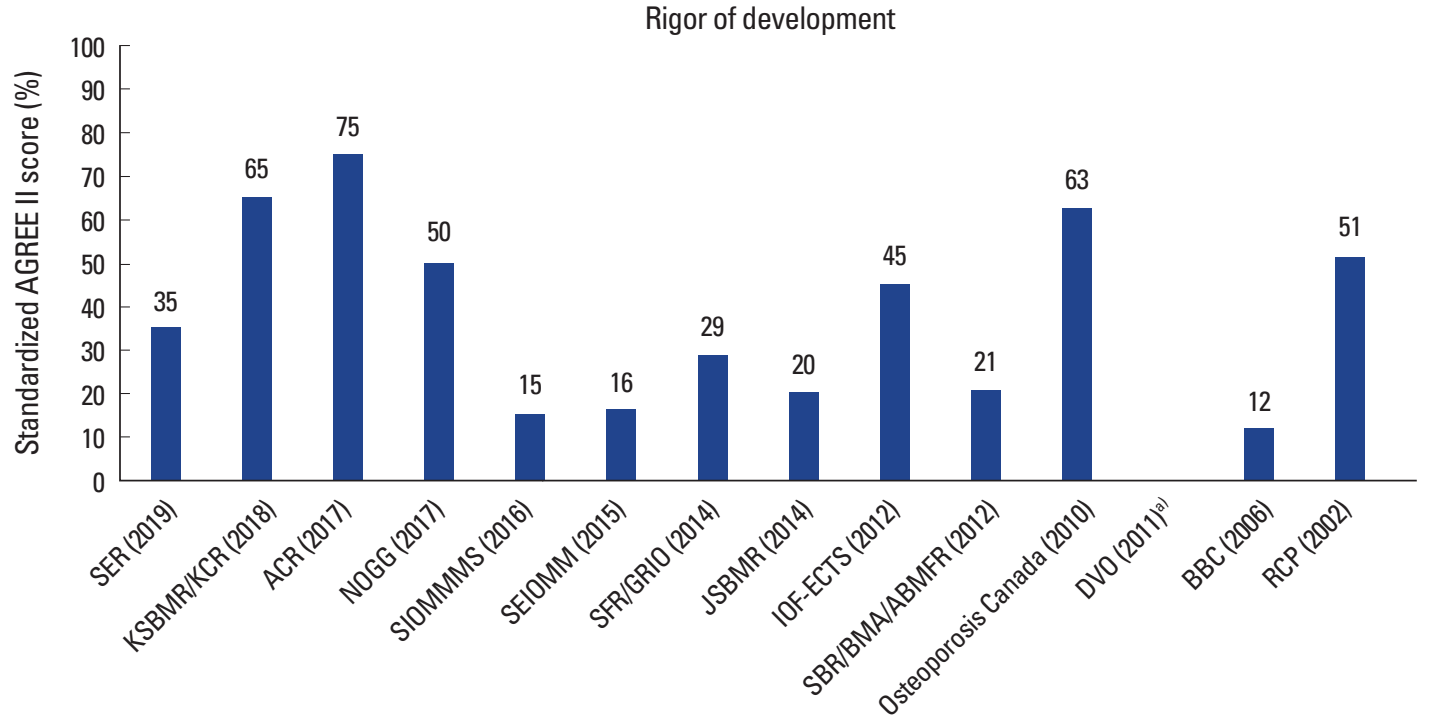

Supplementary Appendix 2. Standardized Appraisal of Guidelines for Research and Evaluation II (AGREE II) domain score for rigor of development in each guideline. alExcluded from the assessment because the development process was provided in German only. SER, Spanish Society of Rheumatology; KSBMR/KCR, Korean Society for Bone and Mineral Research/Korean College of Rheumatology; ACR, American College of Rheumatology; NOGG, National Osteoporosis Guideline Group; SIOMMMS, Società Italiana dell'Osteoporosi del Metabolismo Minerale e delle Malattie dello Scheletro; SEIOMM, Sociedad Española de Investigación Ósea y Metabolismo Mineral; SFR/GRIO, French Society for Rheumatology and Osteoporosis Research and Information Group; JSBMR, Japanese Society for Bone and Mineral Research; IOF-ECTS, International Osteoporosis Foundation and the European Calcified Tissue Society; SBR/BMA/ABMFR, Brazilian Society of Rheumatology/Brazilian Medical Association/Brazilian Association of Physical Medicine and Rehabilitation; DVO, Dachverband Osteologie e. V.; BBC, Belgium Bone Club; RCP, Royal College of Physicians. 
| Tae-Han Lee, et al.

Supplementary Appendix 3. Summary of development methodologies of the guidelines with the AGREE II rigor score of $50 \%$ or above

\begin{tabular}{|c|c|c|c|c|c|}
\hline References & Guideline & Year & Method to search for evidence & $\begin{array}{l}\text { Method to formulate } \\
\text { recommendations }\end{array}$ & $\begin{array}{l}\text { Method to evaluate the } \\
\text { quality of evidence }\end{array}$ \\
\hline Park et al. [12] & KSBMR/KCR & 2018 & $\begin{array}{l}\text { Systematic review of published guide- } \\
\text { lines }\end{array}$ & Expert consensus & AGREE II \\
\hline Buckley et al. [11] & ACR & 2017 & Systematic review of RCTs & $\begin{array}{l}\text { Expert consensus based on } \\
\text { a voting process using Poll } \\
\text { Everywhere software }\end{array}$ & Cochrane risk of bias tool \\
\hline Compston et al. [10] & NOGG & 2017 & $\begin{array}{l}\text { Systematic review (review of RCTs, } \\
\text { systematic review, meta-analyses) }\end{array}$ & Not mentioned & AMSTAR \\
\hline Papaioannou et al. [18] & $\begin{array}{l}\text { Osteoporosis } \\
\text { Canada }\end{array}$ & 2010 & $\begin{array}{l}\text { Systematic review (review of pub- } \\
\text { lished RCTs, cohort studies, system- } \\
\text { atic reviews, meta-analyses) }\end{array}$ & $\begin{array}{l}\text { Expert consensus based on a } \\
\text { modified RAND/University of } \\
\text { California, Los Angeles Del- } \\
\text { phi method }\end{array}$ & Not mentioned \\
\hline $\begin{array}{l}\text { Bone and Tooth Society } \\
\text { of Great Britain et al. } \\
\text { [15] }\end{array}$ & $\mathrm{RCP}$ & 2002 & Systematic review of RCTs & Not mentioned & Cochrane risk of bias tool \\
\hline
\end{tabular}

KSBMR/KCR, Korean Society for Bone and Mineral Research/Korean College of Rheumatology; ACR, American College of Rheumatology; NOGG, National Osteoporosis Guideline Group; RCP, Royal College of Physicians; RCTs, randomized controlled trials; AGREE II, Appraisal of Guidelines for Research and Evaluation II; AMSTAR, Assessment of Multiple Systematic Reviews. 